\title{
Diverse Synaptic Terminals on Rat Stapedius Motoneurons
}

\author{
Daniel J. Lee, ${ }^{1,2,3}$ Thane E. Benson, ${ }^{1}$ and M. Christian Brown ${ }^{1,3}$ \\ ${ }^{1}$ Department of Otolaryngology, Eaton-Peabody Laboratory, Massachusetts Eye and Ear Infirmary, Boston, MA, USA \\ ${ }^{2}$ Department of Otolaryngology, UMass Memorial Medical Center, Worcester, MA, USA \\ ${ }^{3}$ Department of Otology and Laryngology, Harvard Medical School, Boston, MA, USA
}

Received: 1 February 2008; Accepted: 21 April 2008; Online publication: 18 June 2008

\begin{abstract}
Stapedius motoneurons (SMN) mediate the contraction of the stapedius muscle, which protects the inner ear from injury and reduces the masking effects of background noise. A variety of inputs to SMNs are known to exist, but their terminal ultrastructure has not been investigated. We characterized the synaptic terminals on retrogradely labeled SMNs found just ventromedial to the facial motor nucleus. About $80 \%$ of the terminals contained round synaptic vesicles. One type ( $\mathrm{Sm}$ Rnd) had small, round vesicles filling the terminal with occasional dense core vesicles and formed an asymmetric synapse. Sm Rnd terminals were small with lengths of apposition to the SMN less than $3 \mu \mathrm{m}$. Partial reconstructions from serial sections demonstrated that these terminals formed up to three synapses per terminal. Another terminal type (Lg Rnd) had large, round vesicles and asymmetric synapses. Most Lg Rnd terminals were small but some were extensive, e.g., abutting the SMN for up to $10 \mu \mathrm{m}$. One of these terminals formed at least seven synapses. Another terminal type (Pleo) had pleomorphic vesicles and symmetric active zones that, in some cases, were invaginated by spines from the SMN. A fourth uncommon terminal type (Het Rnd) had round vesicles of heterogeneous sizes and asymmetric synapses. A fifth rare terminal type (Cist) had large, round vesicles and an accompanying subsurface cistern in the SMN. These were generally the same
\end{abstract}

Presented at the February 2007 ARO Midwinter Meeting, Denver, Colorado.

Correspondence to: Daniel J. Lee - Department of Otolaryngology, Eaton-Peabody Laboratory - Massachusetts Eye and Ear Infirmary . Boston, MA 02114, USA. Telephone: +1-617-5736391; fax: +1-6177204408; email: daniel_lee@meei.harvard.edu kinds of terminals found on other motoneurons, but the high proportion of round vesicle synapses indicate that SMNs receive mostly excitatory inputs.

Keywords: stapedius muscle, acoustic reflex, vesicle, electron microscopy

\section{INTRODUCTION}

The stapedius and tensor tympani are the two middle ear muscles. The stapedius in humans is the primary middle ear muscle that contracts in response to sound (Brask 1979; Ochi et al. 2002). The contraction of the stapedius muscle decreases the transmission of sound into the inner ear (Gelfand 2002), and this action is protective (Hilding 1960; Brask 1979). For example, patients who have a unilateral facial nerve paralysis because of Bell's palsy are unable to contract the stapedius, which is innervated by a branch of the facial nerve. When these patients are exposed to acoustic overstimulation in both ears, they have a higher incidence of a temporary hearing loss in the ear ipsilateral to the paralysis compared with the other ear (Brask 1979). The stapedius muscle's contraction may also prevent the masking of speech information by background noise (Stevens and Davis 1938; Borg and Zakrisson 1974, 1975; Mahoney et al. 1979; Borg et al. 1984).

The contraction of the stapedius muscle is mediated by stapedius motoneurons (SMNs). Labeling studies show that there are over 1,100 SMNs spread over several perifacial and periolivary regions in the cat (Lyon 1978; Joseph et al. 1985). SMNs are located both ventromedially and dorsomedially to the facial nucleus in guinea pig (Strutz et al. 1988) and rat (Rouiller et al. 1989). They are spatially organized 
around the motor nucleus of the facial nerve in a pattern according to their physiologic responses to sound presented to the ipsilateral or contralateral ear (McCue and Guinan 1988; Vacher et al. 1989). The neuronal pathway leading to the SMNs proceeds through the ventral cochlear nucleus (Borg 1973; Lee et al. 2006). From here, the pathway may proceed through the superior olivary complex (Borg 1973; Rouiller et al. 1989). However, the exact identity of the neurons mediating the stapedius reflex is still under investigation.

In addition to sound-evoked, reflexive inputs, SMNs receive other inputs. The middle ear muscles contract in response to self-generated vocalization (Borg and Zakrisson 1975), perhaps as part of the motor planning stage of vocalization, a process that may minimize self-stimulation. Serotoninergic terminals on SMNs may modulate reflexive contractions of the stapedius muscle (Thompson et al. 1998). Finally, higher brain centers may also provide conscious control over the stapedius reflex (Nomura et al. 1979; Borg et al. 1984; Gelfand 1984; Moller 1984; Stach et al. 1984; Gelfand 1998). The sources of these descending inputs to SMNs are not known.

We hypothesize that the diversity of inputs to SMNs is reflected in a variety of types of axon terminals that synapse on SMNs. This study is the first characterization of the ultrastructural features of synapses on SMNs. Our experimental approach was to intensively examine a limited series of serial sections in SMNs and reconstruct their terminals to understand the morphology in all dimensions. We chose SMNs from the largest group, ventromedial to the facial nucleus (Fig. 1). In cats, neurons of this ventromedial group respond to contralateral sound (Vacher et al. 1989). Our results on rat SMNs reveal at least five different types of synaptic terminals, each of which is likely to originate from a distinct source.

\section{MATERIALS AND METHODS}

\section{Retrograde labeling of stapedius motoneurons}

All experimental procedures on animals were performed in accordance with the National Institutes of Health guidelines for the care and use of laboratory animals as well as approved animal care and use protocols at the Massachusetts Eye and Ear Infirmary and Harvard Medical School.

The present study used three adult male SpragueDawley rats (420 to $437 \mathrm{~g}$ ). Before surgery, each rat was anesthetized with ketamine $(100 \mathrm{mg} / \mathrm{kg}$, i.p.) and xylazine (10 mg/kg i.m.) Boosters were administered as needed. The level of anesthesia was monitored by respiratory rate, paw-pinch withdrawal reflex, response to surgical manipulation, and core body

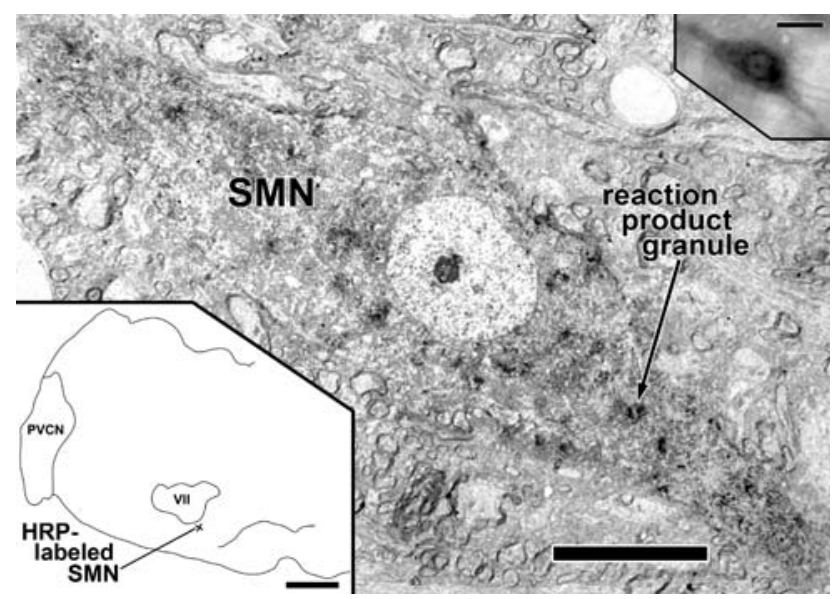

FIG. 1. HRP-labeled SMN. Center image: low magnification electron micrograph of $S M N$ (neuron R1) with reaction product granules (one indicated) and diffuse darkening of the cytoplasm. Lower left: drawing of the left half of a coronal section of a rat brainstem showing the location of the SMN ventromedial to the left motor nucleus of the facial nerve (VII). The pyramidal tract is outlined at the midline. PVCN posteroventral cochlear nucleus. Upper right: brightfield photomicrograph of the epoxy-embedded labeled SMN in an $80-\mu \mathrm{m}$ thick Vibratome section. Scale bar $=10 \mu \mathrm{m}$ (center image), scale bar $=1 \mathrm{~mm}$ (lower left), scale bar $=25 \mu \mathrm{m}$ (upper right).

temperature. Body temperature was monitored by a rectal probe and maintained at $37 \pm 1^{\circ} \mathrm{C}$. A postauricular surgical approach of the left ear with partial removal of the bulla was used for exposure of the stapedius muscle belly. This surgical approach preserved the integrity of the facial nerve through the middle ear and outside the bulla. All injections were made into the left stapedius muscle only. Dental pledgets were placed into the surrounding middle ear cleft to minimize spread of tracer. The sheath of the stapedius muscle was pierced with an insect pin, and then $1 \mu \mathrm{l}$ of horseradish peroxidase (HRP, 30\% solution in $0.01 \mathrm{M}$ Tris buffer, $\mathrm{pH}$ 8.6) was injected into the muscle belly using a 32-gauge beveled needle tip mounted on a 5 - $\mu$ l Hamilton syringe. The postauricular surgical incision was closed and the animal was allowed to recover.

\section{Tissue processing and electron microscopy}

After a survival time of $24 \mathrm{~h}$, the animals were reanesthetized and perfused transcardially with $0.1 \%$ sodium nitrite in physiologic saline followed by $0.5 \%$ paraformaldehyde and $1 \%$ glutaraldehyde in $0.1 \mathrm{M}$ cacodylate buffer. This was followed by $0.5 \%$ paraformaldehyde and 3\% glutaraldehyde in buffer. The brainstem was blocked, embedded in a gelatinalbumin mixture $(0.5 \%$ and $27 \%$, respectively), hardened with $2.3 \%$ glutaraldehyde, and sectioned at 
$80 \mu \mathrm{m}$ thickness on a Vibratome in the transverse plane. Free-floating sections were processed to yield reaction product that is stable and electron dense for ultrastructural analysis (Blok et al. 1995). Briefly, Vibratome sections were presoaked in a solution of tetramethylbenzidine and ammonium heptamolybdate (Olucha et al. 1985) in $0.1 \mathrm{M}$ phosphate buffer made hypertonic with dextrose. Hydrogen peroxide $(0.3 \%, 1 / 100 \mathrm{ml})$ was then added every $5 \mathrm{~min}$ for $20 \mathrm{~min}$. The sections were moved to fresh incubation solution, and $\mathrm{H}_{2} \mathrm{O}_{2}$ was again added to allow a more dense reaction product with minimal crystal artifact. Selected sections with labeled SMNs were treated overnight with hypertonic $\mathrm{OsO}_{4}\left(\mathrm{pH} 5\right.$ at $3{ }^{\circ} \mathrm{C}$; Henry et al. 1985). The sections were stained en bloc with saturated, filtered $1 \%$ uranyl acetate (overnight at $3^{\circ} \mathrm{C}$ ), dehydrated with methanol, infiltrated with epoxy, and flat-embedded between two transparent sheets of Aclar (Pro Plastics, Wall, NJ, USA).

Sections were first examined using the light microscope. Specimens were selected for further study if they contained darkly labeled SMN somata. Detailed camera lucida drawings were made of the selected sections. On the drawings, we indicated the SMNs and their depths within the section, as well as fiducial marks such as labeled and unlabeled fibers, unlabeled somata, blood vessels, red blood cells, tissue imperfections, and the section boundaries. Photomicrographs were taken at a number of different focal planes to provide information that was complementary to the drawings. Then, a region ventromedial to the motor nucleus of the facial nerve containing labeled SMNs was cut away, remounted on an epoxy blank, and sectioned with a diamond knife and an ultramicrotome (DuPont Sorval MT 2B) at $\approx 80 \mathrm{~nm}$ thickness. Short series of serial ultrathin sections were collected on Formvar-coated slot grids.

Without further staining, sections were examined in the electron microscope (EM; Phillips CM 10) at $\times 1,200$ to $\times 21,000$. Images were captured using a digital camera (Model 8C, Scientific Instruments and Applications, Duluth GA, USA) in .tiff format. A scale bar previously generated from a calibrated diffraction grating replica was a component of the data bar for each image file. The 16-bit images were processed using the Levels function of Adobe Photoshop CS to achieve brightness and contrast akin to our previous analog images (Benson and Brown 2006). To achieve optimal focus and detail, the Photomerge feature of Photoshop CS was sometimes used to rejoin features in a section that continued beyond the field of view of a single high-magnification micrograph (e.g., Fig. 5A and $\mathrm{B}$ ). For illustrative purposes, selected neuronal elements were outlined in Photoshop using a WACOM graphics tablet (Model CTE-440) and pseudocolored with a $20-30 \%$ color fill.

\section{Morphometric analyses of synaptic vesicles}

In selected terminals, the size and circularity of all synaptic vesicles within $1 \mu \mathrm{m}$ of the synaptic specializations in all available sections were measured. This included some sections adjacent to those containing the specialization. In those sections, the cutoff was $1 \mu \mathrm{m}$ from the membrane in apposition with the SMN. Using the graphics tablet with Image J (v. 1.36 b, $\mathrm{NIH}$ ), vesicle size (area) and shape (circularity= $4 \pi\left(\right.$ area/perimeter $\left.{ }^{2}\right)$ were measured by tracing the outer edge of the vesicle membrane. Mean and standard error of the mean (SEM) were calculated. Vesicle counts were not adjusted to account for the possibility of counting the same vesicle twice in contiguous sections.

\section{Reconstructions}

Each terminal was assigned an identifier and reconstructed through the serial sections. Whenever a synapse was found, it was documented in a highmagnification image. Terminal appositions were measured in sections containing the synaptic specialization; if a terminal had synapses in several sections, the one with the longest apposition was chosen for measurement. Minute glial processes (less than $0.05 \mu \mathrm{m}$ ) that intervened for a portion of the apposition of the largest terminals were ignored for the measurement.

A three-dimensional reconstruction (Fig. 5) of one terminal and the associated portion of a SMN was accomplished as follows: Outlines of 21 serial profiles including synapses were digitized and the .tiff files entered into Amira 4.1 (Mercury Computer Systems, San Diego, CA, USA) as a size-calibrated image stack. Section thickness of $80 \mathrm{~nm}$ was used. Profiles in the stack were aligned using the autoalign feature of Amira. A polygonal surface model was then generated and simplified by Amira subroutines. To retain the impression of the series of sections, the model was not smoothed.

\section{RESULTS}

\section{Correlation of light and electron microscopy}

In the light microscope, reaction product granules from retrogradely transported HRP were visible in labeled SMNs (Fig. 1). Reaction product granules were scattered in the somatic and proximal dendritic cytoplasm and there was diffuse cytoplasmic darkening as well. All labeled SMNs were found ipsilateral to the side of injection, just outside the magnocellular core of the facial nucleus, as described previously (Lyon 1978; Joseph et al. 1985; Thompson et al. 1985; 
Guinan et al. 1989; Rouiller et al. 1989). They ranged in size from 10 to $15 \mu \mathrm{m}$ (minor axis) and 30 to $40 \mu \mathrm{m}$ (major axis). Proximal dendrites usually extended from the long axes of the somata (Fig. 1). The majority of labeled SMNs was found in a region ventromedial (Fig. 1, lower left) to the facial motor nucleus, and fewer SMNs were observed dorsolaterally and dorsomedially, consistent with previous observations (Rouiller et al. 1989). From three different rats, we selected four labeled SMNs located ventromedial to the facial nucleus for examination under the electron microscope. The neurons were selected on the basis of being well-labeled, having cell bodies contained within the thick section, and being relatively isolated from other labeled neurons. Neurons included in our study were designated R1, R2, R3.1, and R3.2 (the last two labeled SMNs are from the same animal). Scattered non-SMN labeling was seen in the ipsilateral salivatory nucleus in some cases, consistent with nonspecific retrograde labeling of the cell bodies that give rise to parasympathetic efferent fibers of the chorda tympani nerve.

Using fiducial landmarks, we correlated labeled SMNs in light microscopic drawings and photomicrographs with electron microscopic images taken from ultrathin sections in the same location. Figure 1 shows the same retrogradely labeled SMN in a photomicrograph (upper right inset) and an electron micrograph (main part of the figure). The similarities in the light and electron microscopic views included the shape of the soma and nucleus, presence of a prominent nucleolus, the two major proximal dendrites and their longitudinal orientation, and the degree of labeling. Under low-power electron microscopy, ultrastructural features of labeled SMNs included dark reaction product granules, prominent nuclei and nucleoli, and numerous organelles (Fig. 1). Organelles were oriented parallel to the axes of dendrites or circumferentially in the soma, and this allowed us to define the boundary between these two structures. The number of serial sections available for study ranged from 13 to 22 for the four SMNs studied (although in each series, one to two sections were not available because of technical problems). Assuming that the neuron was an oblong spheroid, we estimate that the portion of the soma examined ranged from $8 \%$ to $12 \% \quad(\mathrm{R} 1=12 \%$, $\mathrm{R} 2=10 \%$, R3.1 $=8 \%$, and R3.2=12\%).

Neuropil surrounding SMNs included abundant myelinated axons, some as large as $2.5 \mu \mathrm{m}$ in diameter; small, unmyelinated axons; and dendrites and axon terminals.

\section{Types of synaptic terminals}

Under high-power examination, we found terminals with synaptic features contacting the soma and proximal dendrites of SMNs. We required the following three features to be present for designating a synapse: (1) flocculent material (postsynaptic density) decorating the membrane of the postsynaptic element and facing the cytoplasm of the SMN, (2) a uniform cleft bounded by the presynaptic and postsynaptic membranes, and (3) a vesicle within a vesicular diameter of the presynaptic active zone (Fig. 2). A long subsynaptic cistern as described in cat spinal motoneurons (Conradi et al. 1979) could substitute for the postsynaptic density.

We grouped synapses into types based on several characteristics of their appearance as has been done previously for central synapses (Schwartz and Gulley 1978; Cant and Morest 1979; Benson et al. 1996). When an individual terminal that formed a particular type of synapse was followed through successive sections in the series and found to form other synapses, they were always of the same type. Thus, our terminology for synapse types will transfer to that for terminals. Our data set included a total of 133 synapses formed from 75 terminals.

Sm Rnd terminals. The first terminal type was packed with clear vesicles and also contained a few dense core vesicles. In measurements from one terminal, the clear vesicles had a mean area of $1,110 \mathrm{~nm}^{2}(\mathrm{SEM}=$ $\left.11 \mathrm{~nm}^{2}, n=459\right)$. Vesicles of this average size would be called "small" in the literature on terminals from the cochlear nucleus (Cant 1993). These vesicles appeared circular in shape and the measurements indicated a mean circularity of $0.90 \quad(\mathrm{SEM}=0.002)$. Our moniker for these terminals, Sm Rnd, derives from the appearance of these synaptic vesicles. However, another important characteristic that we
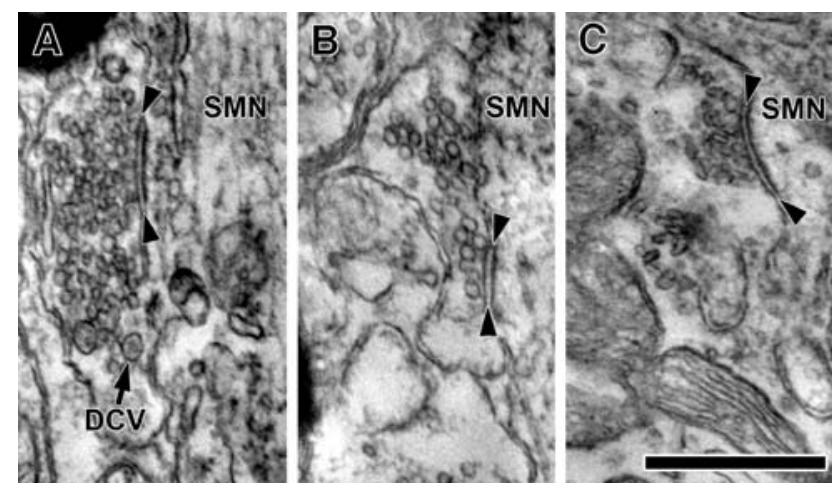

FIG. 2. Representative electron micrographs showing three major terminal types forming synapses on SMNs. A Sm Rnd synaptic terminal densely packed with small, round vesicles and containing a few dense core vesicles (one indicated with DCV). B Lg Rnd synaptic terminal containing large, round vesicles. C Pleo synaptic terminal with pleomorphic vesicles. A cleft of uniform width and a postsynaptic density in the $S M N$ is seen in each example, designated by arrowheads. The terminals shown in this figure were found on SMN R2. Scale bar $=0.25 \mu \mathrm{m}$. 
used as part of their definition was the presence of dense core vesicles (Peters et al. 1991). The dense core vesicles were about $80 \mathrm{~nm}$ in diameter (Figs. 2 and $3 \mathrm{~B}$ ). They were infrequent and were seen in about every third or fourth section of Sm Rnd terminals. The central opacity of these dense core vesicles is light, presumably because our material is stained en bloc (see the "Materials and methods" section). Dense core vesicles of this small size have been associated with the assembly of the presynaptic active zone (Sorra et al. 2006). Sm Rnd synapses were asymmetric, exhibiting prominent postsynaptic material (Figs. 2 and 3A). They were punctate with a flat or concave face with respect to the SMN soma (Figs. 2 and $3 \mathrm{~A})$.

Six Sm Rnd terminals that were observed in the greatest number of sections (series of 16-19 serial sections) were reconstructed. These reconstructions demonstrated that terminals formed either two or three synapses on an SMN. Additional synapses with dendrites in the neuropil were also observed (data not shown). Sm Rnd terminals were relatively small. We measured the size of terminals using the lengths of their appositions with the SMNs in sections containing the synapses. Sm Rnd apposition lengths ranged from 0.52 to $2.77 \mu \mathrm{m}$ (mean=1.65 $\mu \mathrm{m}, n=35)$.

Lg Rnd terminals. The second major type of terminal contained larger clear synaptic vesicles but lacked dense core vesicles (Figs. 2B and 3A and D). Measurements of vesicles from one terminal gave a mean area of $1,501 \mathrm{~nm}^{2} \quad\left(\mathrm{SEM}=26 \mathrm{~nm}^{2}, n=122\right)$ and mean circularity of $0.90 \quad(\mathrm{SEM}=0.003)$, which confirmed our visual impression that these vesicles were on average larger than those of Sm Rnd terminals $(p<$ 0.001). Given that vesicles from Sm Rnd and $\mathrm{Lg}$ Rnd synapses overlapped in size and circularity, the presence of a dense core vesicle in Sm Rnd terminals provided a point of distinction. $\mathrm{Lg}$ Rnd terminals also tended to have fewer vesicles than Sm Rnd terminals. Active zones that were seen in $\mathrm{Lg}$ Rnd synaptic terminals were generally curved, punctate (Fig. 4B), and exhibited a distinct asymmetric postsynaptic density.

Reconstructions of the $\mathrm{Lg}$ Rnd terminals revealed that a single terminal could form multiple synapses at different points along its contact with the SMN. One reconstruction of an extensive terminal is shown in Figure 5. The terminal consisted of two main parts that abut the SMN. These parts were connected by a thin process although they appeared separately in some micrographs (Fig. 4A). Together, they form a total of seven synapses on the SMN. An additional minute process $(<0.2 \mu \mathrm{m}$ wide) continues away from the SMN and then thickens to form another synapse on an unidentified dendrite in the neuropil (left part of Figs. 4A and 5). The overall appearance of the terminal was of "beads on a string" (Fig. 4A). This terminal arises from a myelinated (my) process (Fig. 5, lower right), as did one other Lg Rnd terminal (whether the other terminals originated from myelinated axons could not be determined). Through the 13 sections examined in another extensive terminal shown in Fig. 4B, four synapses were found (one is shown in Fig. 4B). In three other Lg Rnd terminals for which a series of 17-19 sections were available, the terminals formed between four and six synapses. More synapses may be present, as these terminals appear to extend well beyond our limited series.

$\mathrm{Lg}$ Rnd terminals were observed in a wide variety of sizes with apposition lengths ranging from 0.97 to $9.33 \mu \mathrm{m}($ mean $=2.77 \mu \mathrm{m}, n=20$; Fig. $3 \mathrm{E}$ and F). Most (Fig. 3A) were small, but a subset of Lg Rnd terminals was larger and, in some cases, much larger. Such extensive terminals can abut the SMN for $9 \mu \mathrm{m}$ or more (Fig. 4B), although this largest contact was not always contiguous as small $(<0.05 \mu \mathrm{m})$ glial processes sporadically intercalated along the membrane. Figure $6 \mathrm{~A}$ and B compares the apposition lengths of Sm Rnd and Lg Rnd terminals, showing the infrequent examples of long apposition lengths of $\mathrm{Lg}$ Rnd terminals.

Pleo terminals. Pleo terminals contained Pleo vesicles (Figs. 2C, 3A, and 4D). The presence of flat vesicles made these terminals distinct and gave their circularity a lower mean and a higher standard error (mean circularity $=0.81 ; \mathrm{SEM}=0.005$ ). Pleo vesicles had a mean area of $1,361 \mathrm{~nm}^{2}(\mathrm{SEM}=19, n=402)$. The other distinct feature of Pleo terminals was their symmetric synapses in which the minimal presynaptic and postsynaptic densities appeared similar (Figs. 3A and $4 \mathrm{D})$. These terminals varied in size and shape and had a mean apposition length that ranged from 0.74 to $2.54 \mu \mathrm{m}$ (mean $=1.57 \mu \mathrm{m}, n=13$; Fig. $6 \mathrm{C})$. Reconstructions demonstrated one to two synapses per terminal. Terminals containing Pleo vesicles occurred in a range of morphologies. Some were densely packed with mitochondria. One third of Pleo terminals were formed around spines extending into them from the SMN (Fig. 4D). Dense core vesicles were rarely observed in Pleo terminals.

Het Rnd terminals. A fourth type of terminal was named heterogeneous round (Het Rnd) because their synaptic vesicles were round and of several sizes. These synaptic terminals were found contacting the proximal dendrites or somata of SMNs R1 and R2 (Figs. 3C and 8). Measurements of vesicles from one Het Rnd terminal gave a mean vesicular area of $1,250 \mathrm{~nm}^{2} \quad(\mathrm{SEM}=18, n=455)$. However, vesicle size distribution exhibited a peak and a "tail" of larger sizes; the great majority of vesicles clustered around $1,200 \mathrm{~nm}^{2}$, and a small minority of vesicles of larger size clustered around 3,200 $\mathrm{nm}^{2}$ (black arrows, Fig. 7). This is not a bimodal distribution of size as there are 

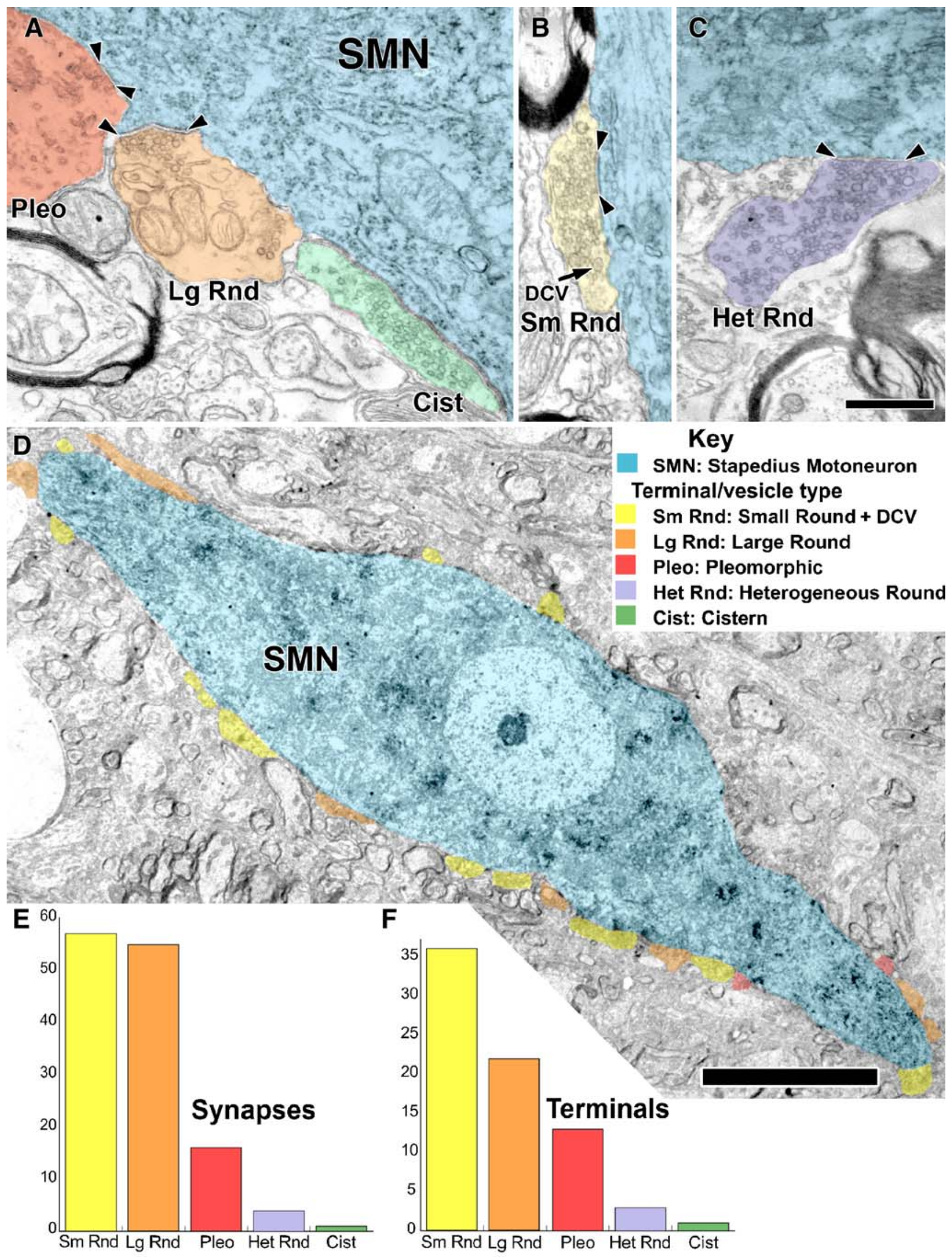

\section{Terminal/vesicle type}

Sm Rnd: Small Round + DCV

Lg Rnd: Large Round

Pleo: Pleomorphic

Het Rnd: Heterogeneous Round

\section{Cist: Cistern}

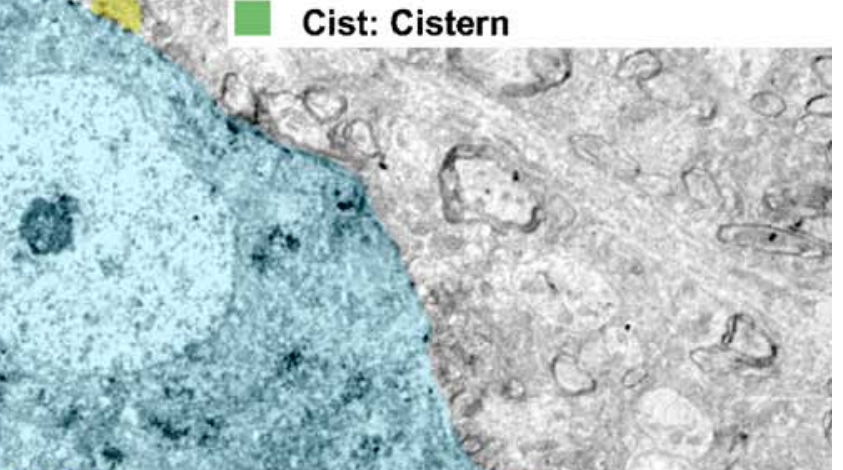

E

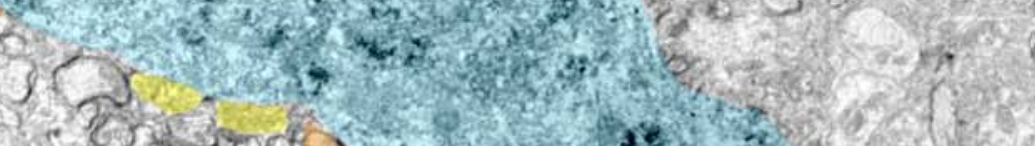

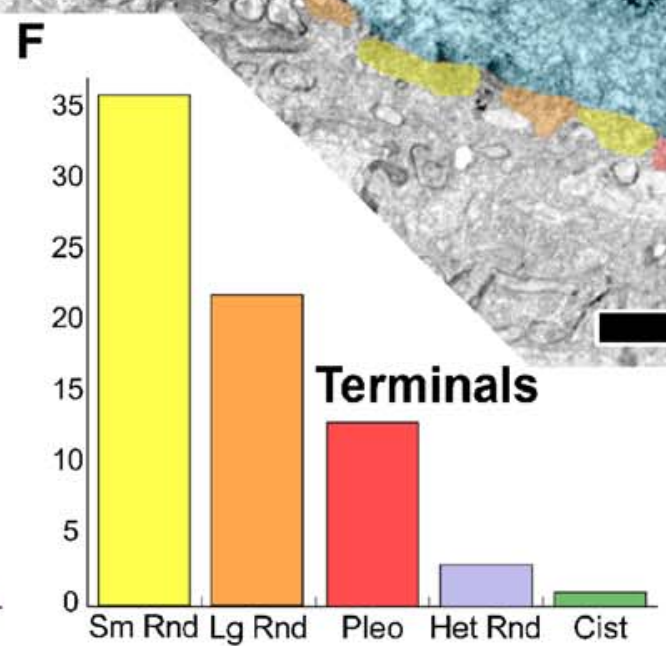

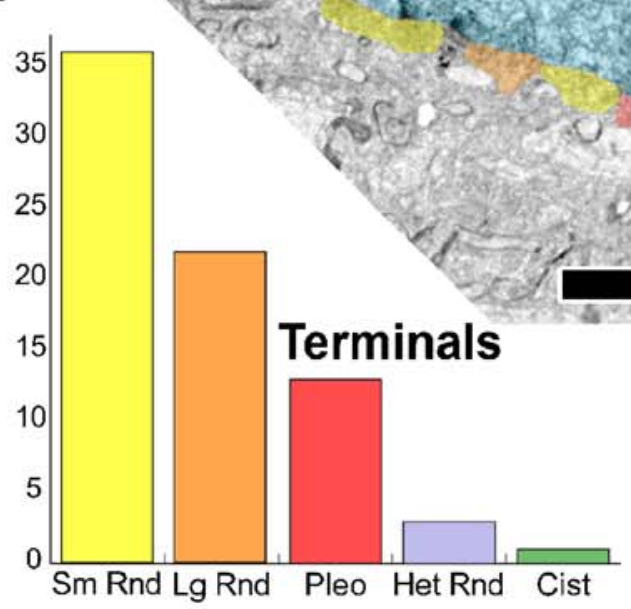


FIG. 3. A-C Five types of synaptic terminals (see Key) on labeled SMNs (cyan). Synapses are marked by arrowheads. A Synaptic terminals with pleomorphic vesicles $(P l e o, r e d)$, with large, round vesicles ( $L g R n d$, orange), or a cistern in the SMN rather than a postsynaptic density (Cist, green). B Synaptic terminal with numerous small, round vesicles ( $S m$ Rnd, yellow) and dense core vesicles (DCV). C Synaptic terminal with round vesicles of heterogeneous sizes (Het Rnd, lavender). D Low magnification electron micrograph showing the distribution of synaptic terminals on the SMN cell body and proximal dendrites. There are $12 \mathrm{Sm}$ Rnd terminals (yellow), $6 \mathrm{Lg}$ Rnd terminals (orange), and 2 Pleo terminals (red) in this section. These synaptic terminals (and other terminals that could not be verified to form synapses) covered $33 \%$ of the membrane of the soma and $44 \%$ of the membrane of the proximal dendrites. Scale bar= $10 \mu \mathrm{m}$. Overall summary of the number of synapses $(\mathbf{E})$ and terminals (F) for the five types: Sm Rnd small, round+DCV; $L g$ Rnd large, round; Pleo pleomorphic; Het Rnd heterogeneous round; Cist cistern. These data are from the four labeled SMNs from all three rats. A-C are from R2, and $\mathbf{D}$ is from R1. Scale bar $=0.5 \mu \mathrm{m}(\mathbf{A}-\mathbf{C})$, scale bar $=$ $10 \mu \mathrm{m}(\mathbf{D})$.

relatively few of these large vesicles compared with smaller vesicles. The size of these smaller vesicles is similar to vesicles of Sm Rnd terminals, and the size of these larger vesicles is larger than those in Lg Rnd terminals. Similar to both $\mathrm{Lg}$ Rnd and Sm Rnd terminals, Het Rnd vesicles were round (mean circularity $=0.91$ ). We observed one synapse per Het Rnd terminal. Synapses were asymmetric and associated with flat postsynaptic densities.

Cist terminals. We found one cistern-type (Cist) synaptic terminal contacting the soma of neuron R2. Rather than a classic postsynaptic density, the terminal had a subsurface/subsynaptic cistern (Figs. 3A and 8). The cistern was continuous with the endoplasmic reticulum. This Cist terminal contained large, round vesicles (mean area $=1,444 \mathrm{~nm}^{2}, \mathrm{SEM}=22, n=329$; Figs. 3A and 8).

\section{Relative frequency of synaptic terminals}

The numbers of synapses and terminals are plotted according to type in Figure $3 \mathrm{E}$ and $\mathrm{F}$ for all data. For the total of 133 synapses (Fig. 3E), 57 (42.9\%) were Sm Rnd, 52 (39.1\%) were Lg Rnd, 16 (12.0\%) were Pleo, 7 (5.3\%) were Het Rnd, and $1(0.7 \%)$ was Cist. For the total of 75 terminals (Fig. 3F), 36 (48.0\%) were Sm Rnd, 21 (28.0\%) were $\mathrm{Lg}$ Rnd, 13 (17.3\%) were Pleo, 4 (5.3\%) were Het Rnd, and 1 (1.3\%) was Cist. Thus, Sm Rnd and Lg Rnd formed approximately equal numbers of synapses, but Sm Rnd composed the clear majority of terminals. This difference arises because Lg Rnd terminals formed more synapses per terminal (up to seven synapses) than Sm Rnd (up to three synapses). In terms of the individual SMNs examined, all four received Sm Rnd, Lg Rnd, and Pleo terminals. Only two SMNs (R1, R2) were seen to receive the less common Het Rnd terminals and only

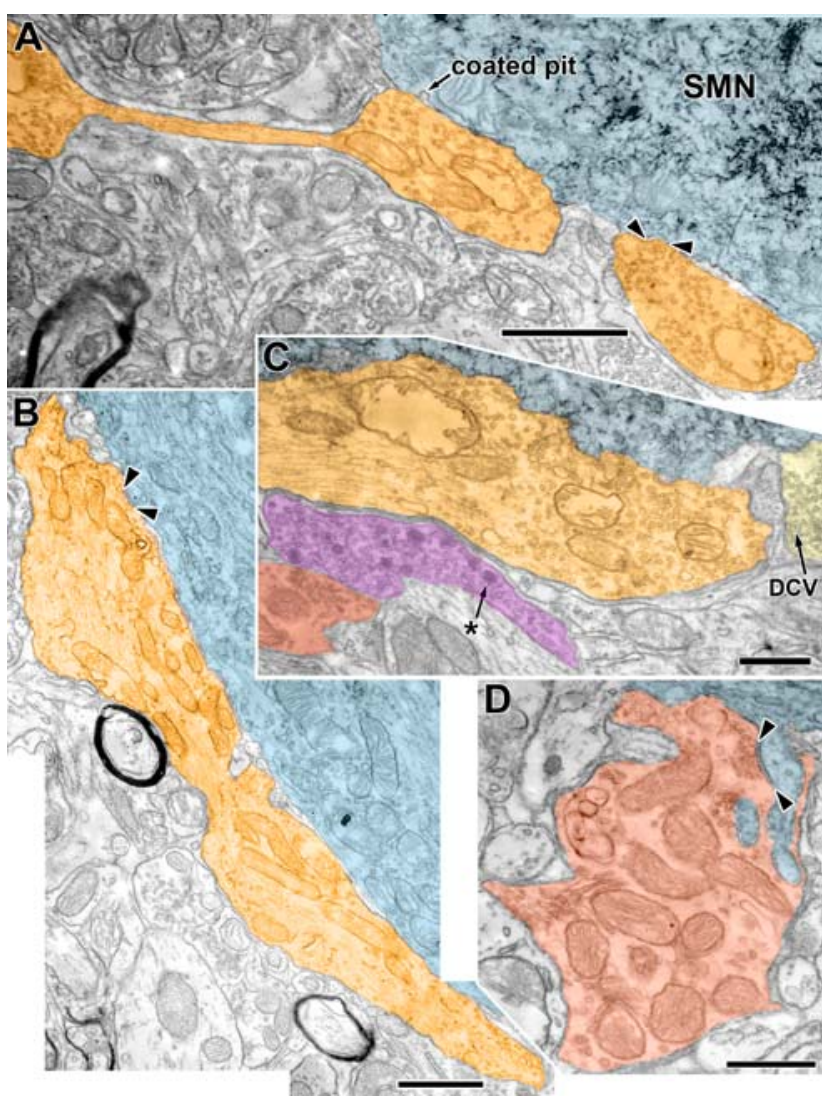

FIG. 4. Electron micrographs showing examples of Lg Rnd and Pleo synaptic terminals. A Lg Rnd terminal (orange) having the appearance of "beads on a string." Two parts of this terminal, connected in another section, abut the SMN (cyan). One synapse, convex with respect to the cytoplasm, is indicated (arrowheads). Another synapse was located near the coated pit (indicated on figure) but two sections removed. Note reaction product granules in the SMN. The image is comprised of two digitally merged photomicrographs. B Another Lg Rnd terminal (orange) that abuts the SMN for over $9 \mu \mathrm{m}$. The abutment is not wholly contiguous in that small glial processes sporadically intercalate. A synapse with a concave postsynaptic density is visible in this section (arrowheads); three other synapses were formed in other sections. This image is comprised of three digitally merged photomicrographs. C A portion of another Lg Rnd (orange). Note that there are abundant synaptic vesicles although there was no synapse in this part of the terminal. There is a separate axonal swelling (magenta) with a mixture of clear vesicles and large granular dense core vesicles (asterisk). The swelling is in the perifacial neuropil and separated from the SMN by the $\mathrm{Lg}$ Rnd terminal. Note that these dense core vesicles are appreciably larger than those in Sm Rnd terminals (yellow, DCV). A Pleo terminal (red) is also visible in the neuropil. D Pleo terminal (red) forming a complex relationship with two finger-like, spinous protrusions of an SMN. One spine is connected to the SMN (shown in this section) and receives a synapse (arrowheads). The other spine was connected to the SMN through the series of sections. Pleo vesicles are clustered at the synapse, although there are not many in the rest of the terminal. Much of the terminal area is taken up by mitochondria. A and $\mathbf{C}$ are from R1; $\mathbf{B}$ and $\mathbf{D}$ are from R2. Scale bar $=1.0 \mu \mathrm{m}(\mathbf{A}$ and $\mathbf{B})$, scale bar $=0.5 \mu \mathrm{m}(\mathbf{C}$ and $\mathbf{D})$.

one SMN (R1) was seen to receive the Cist terminal. There was little difference between the relative proportions of the various terminal and synaptic types onto the somata vs. proximal dendrites (data not 
shown) so the two targets are combined for the bar graphs of Figure 3E and F.

Our data suggest that there are more synapses and terminals onto the proximal dendrites than onto the soma for SMNs. The data set contains 41 (30.8\%) synapses onto the soma and $92(69.2 \%)$ synapses onto proximal dendrites. They were formed by 22 terminals $(29.9 \%)$ contacting the soma and 53 terminals $(70.1 \%)$ contacting the proximal dendrites. These observations cannot be accounted for by a difference in the amount of membrane studied between the soma and dendrites. The lengths of membrane that were examined for soma vs. proximal dendrite is about equal (soma/proximal dendrite ratio $=0.90$, range 0.56-1.06) for the four neurons examined.

Other terminals. We observed another type of axon terminal that came close to but did not abut the labeled SMNs. These terminals were observed in every rat examined, but we did not see them form synaptic specializations. They contained a mixture of clear vesicles and large dense core vesicles with a prominent granular center. These granular vesicles were about $100 \mathrm{~nm}$ in diameter (range 80-134 nm; Fig. 4C) and were noticeably larger than the small dense core vesicles in terminals of the Sm Rnd type.

\section{DISCUSSION}

\section{Diversity of inputs on SMNs}

The ultrastructure of SMNs and their inputs has not been previously described. We now report that SMNs receive five distinct types of synaptic terminals and demonstrate the morphology and frequency of each type. Our separation of the types of terminals was based on the appearance of the synaptic vesicles, the presence of dense core vesicles, and the degree of asymmetry of the postsynaptic density. Reliance on several characteristics is a strength of our "typing" because, for example, the shape of synaptic vesicles is

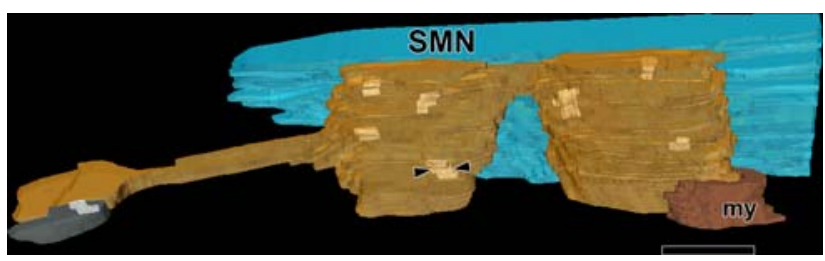

FIG. 5. View of a reconstruction of a terminal (orange) formed onto an SMN (blue, neuron R1). The reconstruction was generated with 21 serial sections, one of which is shown in Fig. 4A. The terminal forms seven synapses on the SMN (light color, one shown by arrowheads). The origin of the swelling is the myelinated stalk visible at the lower right (my, dark orange color). The gray structure at left is an unlabeled dendrite in neuropil that receives a synapse from the reconstructed terminal. Scale bar $=1 \mu \mathrm{m}$.
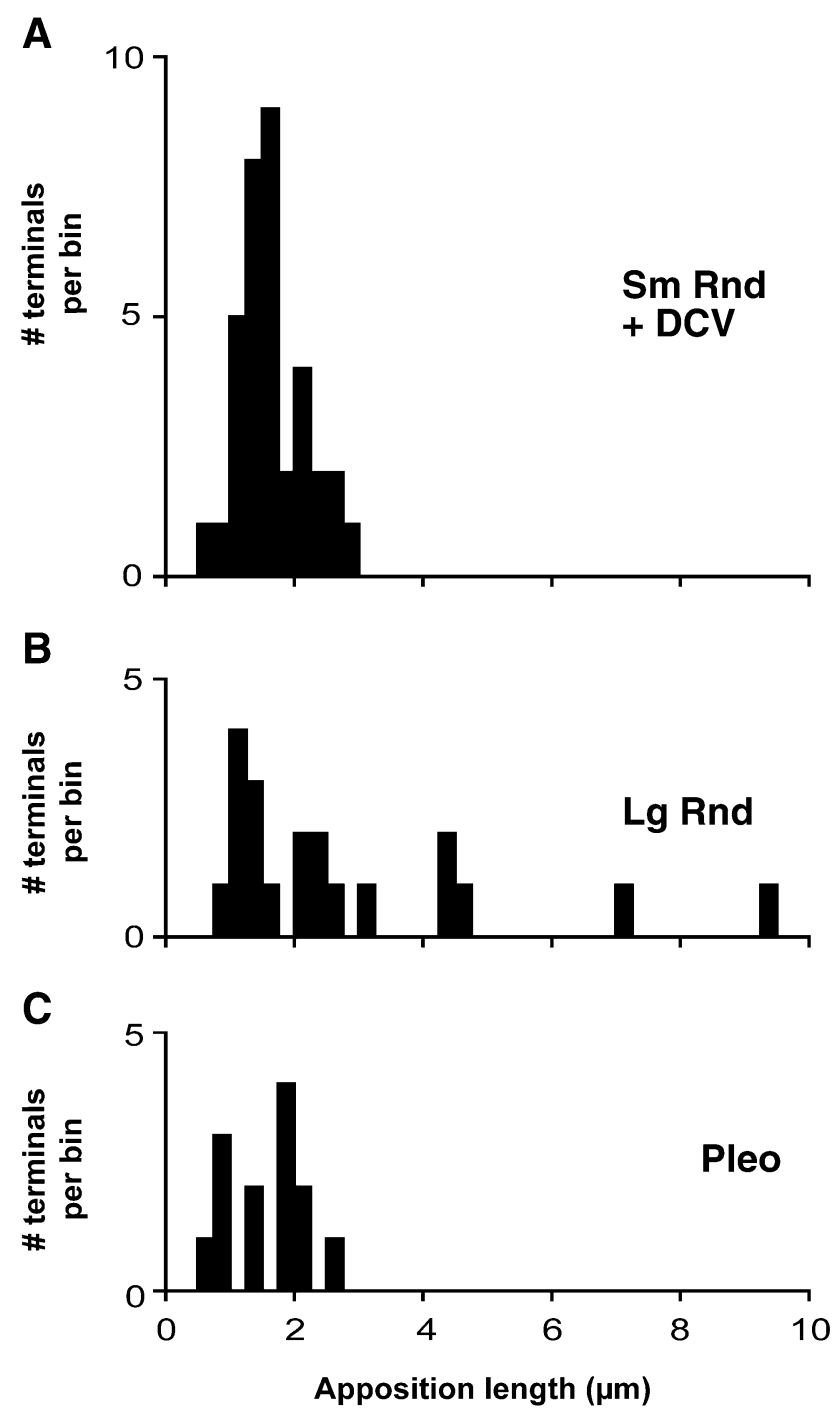

FIG. 6. Apposition lengths for Sm Rnd, Lg Rnd, and Pleo terminals. $\mathrm{Sm}$ Rnd terminals (A) were small with a restricted distribution of apposition lengths ranging from 0.52 to $2.77 \mu \mathrm{m}$ (mean $=1.65 \mu \mathrm{m}$, $n=35)$. In contrast, Lg Rnd terminals (B) had a broader distribution of apposition lengths ranging from 0.97 to $9.33 \mu \mathrm{m}$ (mean $=2.77 \mu \mathrm{m}$, $n=20$ ). Pleo terminals $(\mathbf{C})$, like Sm Rnd terminals, had short apposition lengths (mean $=1.57 \mu \mathrm{m}$, range 0.74 to $2.54 \mu \mathrm{m}, n=13$ ).

known to be affected by the type of fixation used (Valdivia 1971). In our data using a standard fixation protocol, the three common types of terminals were found in each case, suggesting that small fixation differences from animal to animal are not an overwhelming influence on these vesicles. Our size measurements of vesicles from Sm Rnd and Lg Rnd synapses overlapped a great deal, although their means were significantly different. Because packing density differences between terminals could affect our impression of vesicle size, the presence of a dense core vesicle in Sm Rnd terminals becomes an important part of the definition. Without the serial sections used in our study, it would not have been 
possible to use this characteristic because dense core vesicles do not appear in every section.

Another advantage of our serial sections was the ability to follow individual terminals and partially reconstruct them. These observations indicate that Sm Rnd terminals can form up to three synapses and Lg Rnd terminals can form up to seven synapses (Fig. 5). Future analyses that include complete reconstructions of these terminals could yield additional synapses. Lg Rnd terminals are thus a potent source of inputs to SMNs. The substantial distal dendrites of these neurons (Vacher et al. 1989) were not sampled in the present study and so we do not know the nature of inputs present beyond the soma and proximal dendrites.

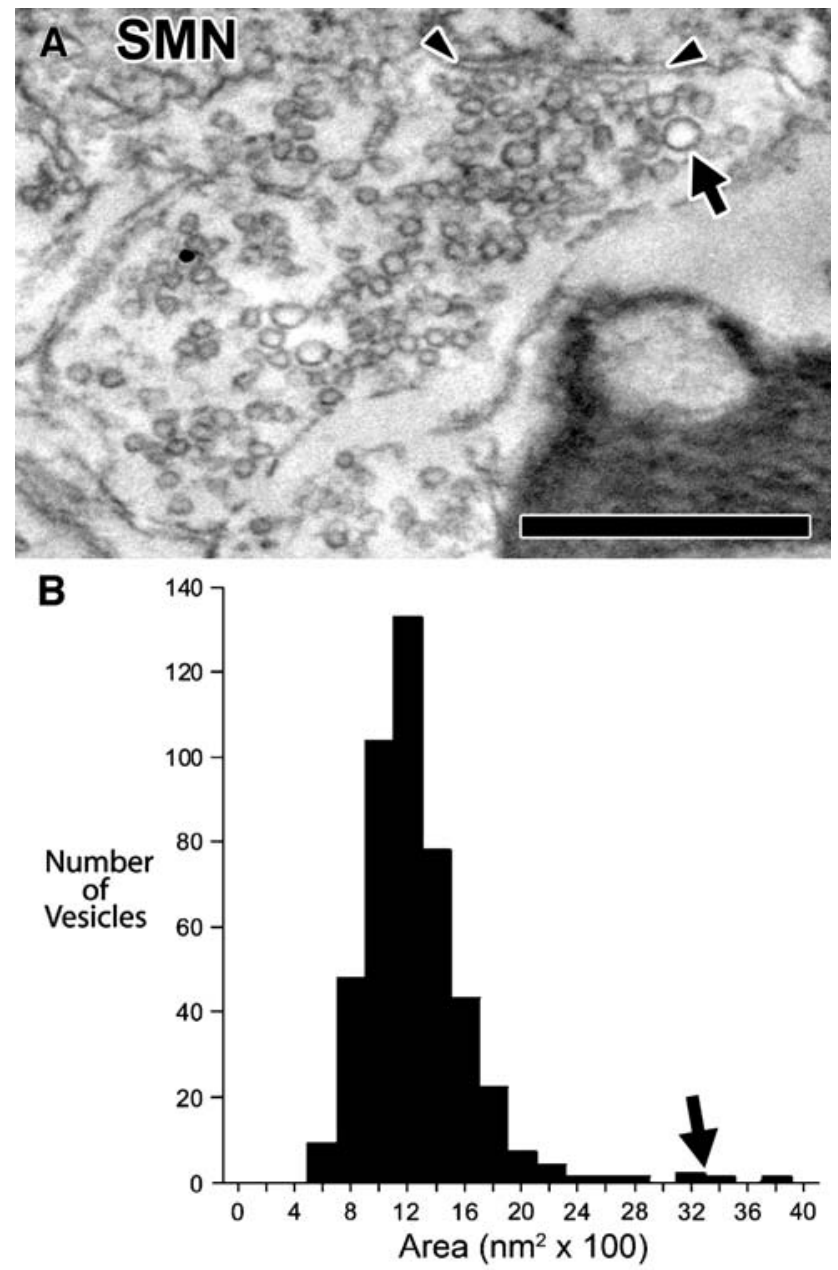

FIG. 7. A High-magnification electron micrograph of a terminal with round vesicles of heterogeneous sizes (Het Rnd, same section as Fig. 3C). A few noticeably large vesicles (arrow) are scattered in the terminal. Arrowheads denote synapse onto SMN R2. Scale bar= $0.5 \mu \mathrm{m}$. B Distribution of vesicle areas for the terminal pictured in A. Most vesicles distribute around $12 \times 100 \mathrm{~nm}^{2}$ but a few larger vesicles distribute around $32 \times 100 \mathrm{~nm}^{2}$ (arrow).

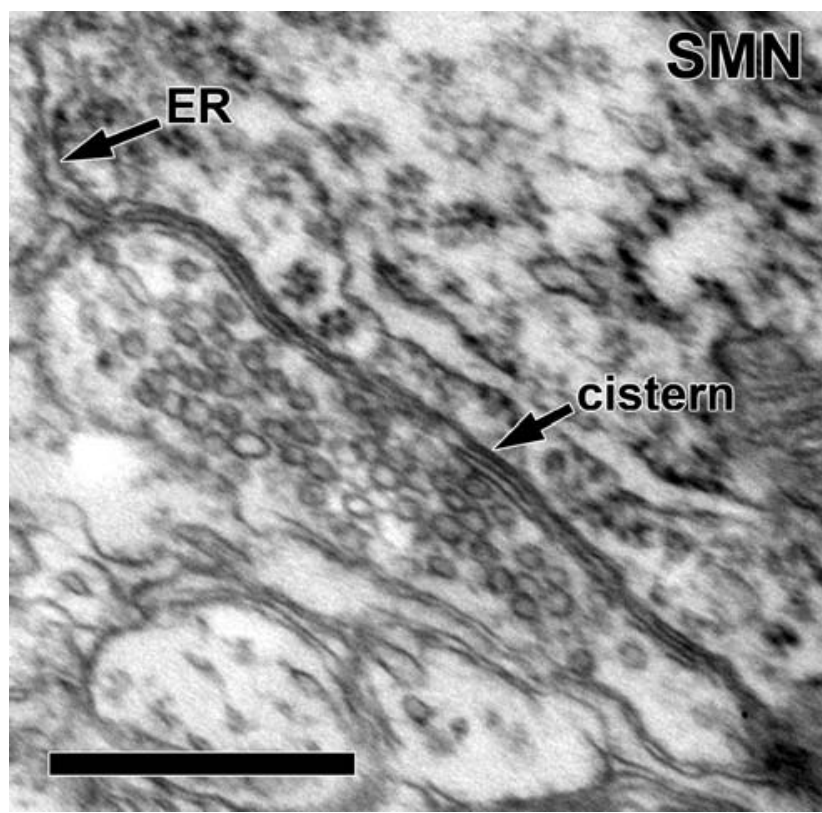

FIG. 8. Detail of a cistern-type (cistern) synaptic terminal on the soma of neuron R2. This is a different section than Fig. 3A. The bilaminar cistern parallels the abutment of the terminal and the $S M N$. Note that the cistern is continuous with the endoplasmic reticulum $(E R)$ of the $S M N$. Large, round vesicles are seen filling the terminal. Scale bar $=0.5 \mu \mathrm{m}$.

It is not clear whether the SMN terminal types might be divided into additional subgroups. For example, most Lg Rnd terminals were of small size but a few were much larger. Perhaps this distinction arises from plane of section: a sausage-shaped terminal could appear large or small. Our series of sections are generally not long enough to settle this issue, but our "beads on a string" terminal directly demonstrates that large terminals may appear small in some sections yet be connected to other parts via thin processes (Figs. 4A and 5). Although two subtypes might be proposed, an argument against this idea comes from the cochlear nucleus where terminals with large, round vesicles originate exclusively from primary auditory nerve fibers, (Gentschev and Sotelo 1973; Treeck and Pirsig 1979). Auditory nerve fibers give rise to many small terminals and a few large endings such as the endbulb of Held, which shows that size classifications might not reliably indicate different sources.

\section{Putative sources of auditory inputs}

SMNs are part of a reflex arc that is excited by sound. The reflexive terminals on SMNs are thus excitatory (presumably containing round vesicles) and are likely to be frequent rather than uncommon. Two types of terminals on SMNs have these requirements: Lg Rnd and Sm Rnd terminals. One idea is that globular 
bushy cells are the source of the Lg Rnd terminals. Large, round vesicles are observed within bushy cell terminals elsewhere in the brainstem (Smith et al. 1991). Some globular bushy cells project to a region where SMNs are found, the nucleus paragigantocellularis lateralis (Warr 1972; Smith et al. 1991). In this region, at least some of their endings are large (Smith, personal communication), large enough to be the size of our Lg Rnd "extensive terminals." The idea that globular bushy cells project to SMNs, though, needs to be tested by tract-tracing or other experiments. Lg Rnd terminals, which form up to seven synapses per terminal, would be expected to exert a powerful influence on the SMN.

Sm Rnd terminals are likely to be from a different source. The superior olivary complex provides input to SMNs (Rouiller et al. 1989; Windsor et al. 2007) and perhaps is part of the stapedius reflex pathway. However, the identity of the participating neuron and its terminal type have not been identified. Stellate/ multipolar neurons of the cochlear nucleus form terminals with small, round vesicles and occasional dense core vesicles similar to those described in this study (Oliver 1987; Smith et al. 1993a, b). However, stellate/multipolar projections to the region of SMNs have not been reported (the small caliber of their axons makes their projections difficult to study). Thus, the origin of the Sm Rnd terminals remains an open question.

Our study included labeled SMNs from the largest group, which is found ventromedial to the motor facial nucleus. Based on data in cat, these SMNs would be expected to receive auditory inputs from the contralateral ear (Vacher et al. 1989). We do not know whether the composition of the terminal types on SMNs vary depending on the location, and future studies will examine the other groups of SMNs that have been shown to respond best to sound from the same ear or either ear (Vacher et al. 1989).

\section{Nonreflexive inputs on SMNs}

The remaining terminal types on SMNs (e.g., Pleo, Het Rnd, and Cist) are likely to arise from nonreflexive inputs. These inputs might arise from the locus coeruleus, cortex, or other centers known to influence middle ear muscle activity (Rouiller et al. 1989; Smith et al. 1991; Thompson et al. 1998; Windsor et al. 2007). These projections have been relatively unexplored. Pleo terminals, which likely inhibit, may decrease the reflexive response to sound. Het Rnd terminals have not been previously reported and their effects are not known. Cist terminals, if they are similar to terminals on spinal $\alpha$-motoneurons, may arise from a source in the spinal cord (McLaughlin 1972; Conradi et al. 1979). A cistern-containing synapse appears in the periphery-efferent terminals on auditory and vestibular hair cells (Jones and Eslami 1983; Holstein et al. 2004). In the auditory periphery, the subsynaptic cistern and associated elements in synapses onto outer hair cells may generate slow effects associated with calcium release (Sridhar et al. 1997). Whether Cist terminals on SMNs exert similar slow effects, or even whether they are excitatory or inhibitory, is unknown.

Axonal terminals containing a mixture of clear and large granular dense core vesicles were seen in the vicinity of SMNs (Fig. 4C), although we did not observe their synapses. The large dense core vesicles are associated with neuroactive peptides and other cotransmitters (Sorra et al. 2006). These terminals may correspond to serotoninergic terminals, which have been reported to contain both clear and granular vesicles (Maxwell et al. 2003). Synapses from these terminals are seen in other regions of the CNS (Maxwell et al. 2003). Immunohistochemical studies demonstrate that SMNs receive serotoninergic inputs that may modulate the nonreflexive contraction of the stapedius (Thompson et al. 1998). MEMs contract in response to chewing or self-generated vocalization (Borg and Zakrisson 1975) and serotoninergic neurons are activated during oral-buccal movements like chewing (Fornal et al. 1996).

\section{A comparison of terminals on SMNs and medial olivocochlear neurons}

The synaptic terminals on other groups of auditory brainstem efferent neurons have, at first glance, some similarities to those terminals on SMNs. For example, like those on SMNs, the major types of terminals on rodent medial olivocochlear (MOC) neurons are those with large, round; small, round; or pleomorphic vesicles (Helfert et al. 1988; Benson and Brown 2006) although cats seem to lack large, round vesicle terminals (Spangler et al. 1987). There are differences, though, that suggest that SMNs and olivocochlear neurons receive inputs from different sources. Two types of SMN terminals (Het Rnd and Cist) were not found on olivocochlear neurons. Nor did olivocochlear neurons receive any terminals comparable to the largest Lg Rnd terminals. Another difference is that the relative proportions of terminal types on SMNs is constant from the soma to the proximal dendrite, whereas on olivocochlear neurons, the large, round terminals become much more frequent on the dendrites (Benson and Brown 2006). Another difference is that the simple spines of SMNs are associated with Pleo terminals, whereas the more complex spines of MOC neurons are associated with large, round vesicle terminals. Differences between SMN and olivocochlear neurons would not be surpris- 
ing given the differences in acoustic response properties of SMNs and olivocochlear neurons. SMNs have high thresholds and broad frequency tuning (Kobler et al. 1992), which may be reflected by the dearth of vesicles at the synapses of extensive $\mathrm{Lg}$ Rnd terminals (Fig. 4B). In contrast, medial olivocochlear neurons have low thresholds and sharp frequency tuning (Robertson and Gummer 1985; Liberman and Brown 1986). Such differences would predict large differences in synaptic inputs to these two types of neurons.

\section{A comparison of terminals on SMNs and other types of motoneurons}

SMNs likely correspond to spinal $\alpha$-motoneurons (rather than $\gamma$-motoneurons) because spindles (innervated by $\gamma$-motoneurons) are rare or absent in the stapedius muscle (Fernand and Hess 1969; van den Berge and van der Wal 1990). Although comparisons between terminal types can be difficult because fixation methods can alter vesicle morphology (Valdivia 1971), the synaptic terminals found on SMNs (Fig. 9) do bear general similarities to those found on

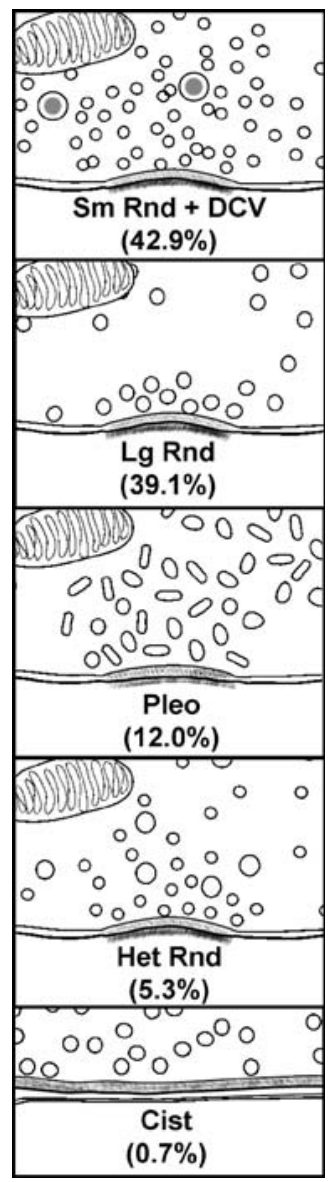

FIG. 9. A summary of the diverse terminal types on SMNs. The SMNs studied were located ventromedial to the facial motor nucleus. Numbers indicate the relative frequency of occurrence (\%). spinal $\alpha$-motoneurons (Conradi et al. 1979; Ichiyama et al. 2006). One type of terminal on spinal $\alpha$ motoneurons contains flattened vesicles (F) and probably corresponds to our Pleo terminals (Conradi et al. 1979; Ichiyama et al. 2006). Our Cist terminal appears to be very similar to Conradi's C type (Conradi et al. 1979). These terminals are uncommon in both systems. Apparently, those on spinal $\alpha$ motoneurons arise from a cholinergic source in the spinal cord (McLaughlin 1972). A similar Cist (G) terminal type has been identified on other motoneuron types within the CNS (Conradi et al. 1979; Saxon et al. 1996; Ichiyama et al. 2006) as well as in the periphery-efferent terminals on auditory and vestibular hair cells (Jones and Eslami 1983; Holstein et al. 2004). Whether Cist terminals on SMNs are excitatory or inhibitory is unknown.

A second type of terminal on spinal $\alpha$-motoneurons contains spherical vesicles (S; Conradi et al. 1979; Ichiyama et al. 2006), and these may correspond in a general way to round vesicle terminals seen on SMNs. An inspection of published micrographs (Conradi et al. 1979; Brannstrom 1993; Ichiyama et al. 2006) suggests that $\mathrm{S}$ terminals contain large vesicles, thus perhaps corresponding best to our Lg Rnd type. We do not know if spinal $\alpha$-motoneurons receive terminals with small, round vesicles, but terminals with large or small, round vesicles do synapse on MOC neurons and there are analogous terminals on cochlear nucleus neurons. In the cochlear nucleus after auditory nerve transection, synaptic terminals containing large, round vesicles disappear (Gentschev and Sotelo 1973; Treeck and Pirsig 1979). If there is a correspondence of terminals on spinal $\alpha$-motoneurons with those on SMNs, we propose it is between large $\mathrm{S}$ terminals and our large, $\mathrm{Lg}$ Rnd terminals. This is an interesting idea because of our suggestion that the largest $\mathrm{Lg}$ Rnd terminals arise from the cochlear nucleus, a sensory input analogous to that of the dorsal root ganglion that provides input on spinal $\alpha$-motoneurons. Another type of S terminal on spinal $\alpha$-motoneurons are called " $M$ " terminals (large terminals containing spherical vesicles that receive presynaptic [P type] terminals and arise from the dorsal root ganglion; Conradi et al. 1979; Saxon et al. 1996; Ichiyama et al. 2006). We did find a single example of a Lg Rnd terminal on an SMN in reciprocal relationship with a "presynaptic input," but the correspondence of this terminal with the "M" type is unclear.

There is a wide range in the proportions of terminal types received by different types of motoneurons. On SMNs, about $80 \%$ of terminals contained round vesicles. On spinal $\alpha$-motoneurons, only $20 \%$ of the terminals contained round vesicles (Kellerth et al. 1979). Motoneurons supplying oculomotor muscles, though, have over $60 \%$ round-vesicle terminals (Tredici et al. 1976), 
and motoneurons supplying laryngeal muscles such as the cricothyroid muscle receive up to $70 \%$ roundvesicle terminals (Hayakawa et al. 1999). These percentages are close to that for SMNs. Terminals containing round vesicles are associated with excitatory inputs (Uchizono 1965). Differences in innervation between SMNs and spinal $\alpha$-motoneurons might be expected. SMNs do not follow the "size principle" order of recruitment (Kobler et al. 1987), there is a high innervation ratio that implies a high degree of motor control (Wiener-Vacher et al. 1999), and the stapedius has no opposing muscle. Further studies will elucidate how SMNs integrate this abundant excitatory input with their minimal inhibitory input.

\section{ACKNOWLEDGMENTS}

We thank Drs. M. Charles Liberman and John J. Guinan Jr. and the many anonymous reviewers for the comments on previous versions of this manuscript, and Dr. Wen $\mathrm{Xu}$ for his technical assistance with this work. This work was supported by the NIH-NIDCD 1 K08 DC06285-01 and RO1 DC01089.

\section{REFERENCES}

Benson TE, Brown MC. Ultrastructure of synaptic input to medial olivocochlear neurons. J. Comp. Neurol 499:244-257, 2006.

Benson TE, Berglund AM, Brown MC. Synaptic input to cochlear nucleus dendrites that receive medial olivocochlear synapses. J. Comp. Neurol 365:27-41, 1996.

Blok BF, De Weerd H, Holstege G. Ultrastructural evidence for a paucity of projections from the lumbosacral cord to the pontine micturition center or M-region in the cat: A new concept for the organization of the micturition reflex with the periaqueductal gray as central relay. J. Comp. Neurol 359:300-309, 1995.

BorG E. On the neuronal organization of the acoustic middle ear reflex: A physiological and anatomical study. Brain Res 49:101$123,1973$.

Borg E, Zakrisson JE. Stapedius reflex and monaural masking. Acta Otolaryngol 78:155-161, 1974.

Borg E, Zakrisson JE. The activity of the stapedius muscle in man during vocalization. Acta Otolaryngol 79:325-333, 1975.

Borg E, Counter SA, Rosler G. Theories of middle ear muscle functions. In: Silman S (ed) The Acoustic Reflex: Basic Principles and Clinical Applications. Orlando, Academic, pp. 63-101, 1984.

Brannstrom T. Quantitative synaptology of functionally different types of cat medial gastrocnemius alpha-motoneurons. J. Comp. Neurol 330:439-454, 1993.

Brask T. The noise protection effect of the stapedius reflex. Acta Otolaryngol. Suppl 360:116-117, 1979.

CANT NB. The synaptic organization of the ventral cochlear nucleus of the cat: The peripheral cap of small cells. In: Merchan MA, Juiz JM, Godfrey DA, Mugnaini E (eds) The Mammalian Cochlear Nuclei: Organization and Function. New York, Plenum, pp. 91$106,1993$.

Cant NB, Morest DK. The bushy cells in the anteroventral cochlear nucleus of the cat. A study with the electron microscope. Neuroscience 4:1924-1945, 1979.
Conradi S, Kellerth JO, Berthold CH. Electron microscopic studies of serially sectioned cat spinal alpha-motoneurons. II. A method for the description of architecture and synaptology of the cell body and proximal dendritic segments. J. Comp. Neurol 184:741-754, 1979.

Fernand VS, Hess A. The occurrence, structure and innervation of slow and twitch muscle fibres in the tensor tympani and stapedius of the cat. J. Physiol 200:547-554, 1969.

Fornal CA, Metzler CW, Marrosu F, Ribiero-do-Valle LE, Jacobs BL. A subgroup of dorsal raphe serotonergic neurons in the cat is strongly activated during oral-buccal movements. Brain Res 716:123-133, 1996.

GELFAnd SA. The contralateral acoustic reflex. In: Silman S (ed) The Acoustic Reflex: Basic Principles and Clinical Applications. Orlando, Academic, pp. 137-186, 1984.

Gelfand SA. Hearing: An Introduction to Psychological and Physiological Acoustics. New York, Marcel Dekker, 1998.

Gelfand SA. The Acoustic Reflex. In: Katz J (ed) Handbook of Clinical Audiology. Lippincott Williams \& Wilkins, Baltimore, pp. 206-232, 2002.

Gentschev T, Sotelo C. Degenerative patterns in the ventral cochlear nucleus of the rat after primary deafferentation. An ultrastructural study. Brain Res 62:37-60, 1973.

Guinan JJ, JR., Joseph MP, Norris BE. Brainstem facial-motor pathways from two distinct groups of stapedius motoneurons in the cat. J. Comp. Neurol 287:134-144, 1989.

Hayakawa T, Zheng JQ, Maeda S, Ito H, Seki M, Yajima Y. Synaptology and ultrastructural characteristics of laryngeal cricothyroid and posterior cricoarytenoid motoneurons in the nucleus ambiguus of the rat. Anat. Embryol. (Berl) 200:301-311, 1999.

Helfert RH, SchWARTz IR, RyAN AF. Ultrastructural characterization of gerbil olivocochlear neurons based on differential uptake of 3H-D-Aspartic acid and a wheatgerm agglutinin-horseradish peroxidase conjugate from the cochlea. J. Neurosci 8:3111-3123, 1988.

Henry MA, Westrum LE, Johnson LR. Enhanced ultrastructural visualization of the horseradish peroxidase-tetramethylbenzidine reaction product. J. Histochem. Cytochem 33:1256-1259, 1985.

Hilding DA. The intratympanic muscle reflex as a protective mechanism against loud impulsive noise. Ann. Otol. Rhinol. Laryngol 69:51-60, 1960.

Holstein GR, Martinelli GP, Boyle R, Rabbitt RD, Highstein SM. Ultrastructural observations of efferent terminals in the crista ampullaris of the toadfish, Opsanus tau. Exp. Brain Res 155:265273, 2004.

IChiYama RM, Broman J, Edgerton VR, Havton LA. Ultrastructural synaptic features differ between alpha- and gamma-motoneurons innervating the tibialis anterior muscle in the rat. J. Comp. Neurol 499:306-315, 2006.

Jones DG, EsLAmi H. An ultrastructural study of the development of afferent and efferent synapses on outer hair cells of the guinea pig organ of Corti. Cell Tissue Res 231:533-549, 1983.

Joseph MP, Guinan JJ, Jr., Fullerton BC, Norris BE, Kiang NY. Number and distribution of stapedius motoneurons in cats. J. Comp. Neurol 232:43-54, 1985.

Kellerth JO, Berthold CH, Conradi S. Electron microscopic studies of serially sectioned cat spinal alpha-motoneurons. III. Motoneurons innervating fast-twitch (type FR) units of the gastrocnemius muscle. J. Comp. Neurol 184:755-767, 1979.

Kobler JB, VACher SR, GuINAN JJ, JR. The recruitment order of stapedius motoneurons in the acoustic reflex varies with sound laterality. Brain Res 425:372-375, 1987.

Kobler JB, Guinan JJ, Jr., Vacher SR, Norris BE. Acoustic reflex frequency selectivity in single stapedius motoneurons of the cat. J. Neurophysiol 68:807-817, 1992.

Lee DJ, de Venecia RK, Guinan JJ, Jr., Brown MC. Central auditory pathways mediating the rat middle ear muscle reflexes. Anat. Rec 288:358-369, 2006. 
Liberman MC, Brown MC. Physiology and anatomy of single olivocochlear neurons in the cat. Hear. Res 24:17-36, 1986.

LYON MJ. The central location of the motor neurons to the stapedius muscle in the cat. Brain Res 143:437-444, 1978.

Mahoney T, Vernon J, Meirle M. Function of the acoustic reflex in discrimination of intense speech. Arch. Otolaryngol 105:119$123,1979$.

Maxwell DJ, KerR R, Rashid S, ANderson E. Characterisation of axon terminals in the rat dorsal horn that are immunoreactive for serotonin 5-HT3A receptor subunits. Exp. Brain Res 149:114124, 2003

McCue MP, Guinan JJ, Jr. Anatomical and functional segregation in the stapedius motoneuron pool of the cat. J. Neurophysiol 60:1160-1180, 1988.

McLaughlin BJ. The fine structure of neurons and synapses in the motor nuclei of the cat spinal cord. J. Comp. Neurol 144:42960, 1972.

MolLer AR. Neurophysiological basis of the acoustic middle-ear reflex. In: Silman S (ed) The Acoustic Reflex: Basic Principles and Clinical Applications. Orlando, Academic, pp. 1-35, 1984.

Nomura Y, Harada T, Fukaya T. Dynamic tympanometry. J. Am. Audit. Soc 4:190-194, 1979.

Ochi K, Ohashi T, Kinoshita H. Acoustic tensor tympani response and vestibular-evoked myogenic potential. Laryngoscope 112:2225-2229, 2002.

OlIVER DL. Projections to the inferior colliculus from the anteroventral cochlear nucleus in the cat: Possible substrates for binaural interaction. J. Comp. Neurol 264:24-46, 1987.

Olucha F, Martinez-Garcia F, Lopez-Garcia C. A new stabilizing agent for the tetramethyl benzidine (TMB) reaction product in the histochemical detection of horseradish peroxidase (HRP). J. Neurosci. Methods 13:131-138, 1985.

Peters A, Palay SF, Webster Hd. The Fine Structure of the Nervous System: Neurons and their Supporting Cells. New York, Oxford University Press, 1991.

Robertson D, Gummer M. Physiological and morphological characterization of efferent neurons in the guinea pig cochlea. Hear. Res 20:63-77, 1985.

Rouiller EM, Capt M, Dolivo M, De Ribaupierre F. Neuronal organization of the stapedius reflex pathways in the rat: A retrograde HRP and viral transneuronal tracing study. Brain Res 476:21-28, 1989

SAXon DW, Robertson GN, Hopkins DA. Ultrastructure and synaptology of the nucleus ambiguus in the rat: The semicompact and loose formations. J. Comp. Neurol 375:109-27, 1996.

SchwartZ AM, Gulley RL. Non-primary afferents to the principal cells of the rostral anteroventral cochlear nucleus of the guineapig. Am. J. Anat 153:489-508, 1978.

Smith PH, Joris PX, Carney LH, YIn TC. Projections of physiologically characterized globular bushy cell axons from the cochlear nucleus of the cat. J. Comp. Neurol 304:387-407, 1991.

SMIth PH, Joris PX, Banks MI, YIN TJ. Responses of cochlear nucleus cells and projections of their axons. In: Merchán MA, Juiz JM, Godfrey DA, Mugnaini E (eds) The Mammalian Cochlear
Nuclei: Organization and Function. New York, Plenum, pp. 349-371, 1993a.

Smith PH, JoRIS PX, YIN TCT. Projections of physiologically characterized spherical bushy cell axons from the cochlear nucleus of the cat: Evidence for delay lines to the medial superior olive. J. Comp. Neurol 331:245-260, 1993b.

Sorra KE, Mishra A, Kirov SA, Harris KM. Dense core vesicles resemble active-zone transport vesicles and are diminished following synaptogenesis in mature hippocampal slices. Neuroscience 141:2097-2106, 2006.

Spangler KM, Cant NB, Henkel CK, Farley GR, Warr WB. Descending projections from the superior olivary complex to the cochlear nucleus of the cat. J. Comp. Neurol 259:452-465, 1987.

SRIDHAR TS, Brown MC, SEwell WF. Unique post-synaptic signaling at the hair cell efferent synapse permits calcium to evoke changes on two time scales. J. Neurosci 17:428-437, 1997.

Stach BA, Jerger JF, Jenkins HA. The human acoustic tensor tympani reflex. A case report. Scand. Audiol 13:93-99, 1984.

Stevens SS, Davis H. Hearing: Its Psychology and Physiology. New York, Wiley, 1938.

Strutz J, Munker G, Zollner C. The motor innervation of the tympanic muscles in the guinea pig. Arch. Oto-rhino-laryngol 245:108-111, 1988.

Thompson GC, Igarashi M, Stach BA. Identification of stapedius muscle motoneurons in squirrel monkey and bush baby. J. Comp. Neurol 231:270-279, 1985.

Thompson AM, Thompson GC, Britton BH. Serotoninergic innervation of stapedial and tensor tympani motoneurons. Brain Res 787:175-178, 1998.

Tredici G, Pizzini G, Milanesi S. The ultrastructure of the nucleus of the oculomotor nerve (somatic efferent portion) of the cat. Anat. Embryol. (Berl) 149:323-346, 1976.

Treeck HH, Pirsig W. Differentiation of nerve endings in the cochlear nucleus on morphological and experimental basis. Acta Oto-laryngol 87:47-60, 1979.

UChizono K. Characteristics of exitatory and inhibitory synapses in the central nervous systems of the cat. Nature 207:642-643, 1965.

VAcher SR, Guinan JJ, JR., Kobler JB. Intracellularly labeled stapedius-motoneuron cell bodies in the cat are spatially organized according to their physiologic responses. J. Comp. Neurol 289:401-415, 1989.

VAlDIVIA O. Methods of fixation and the morphology of synaptic vesicles. J. Comp. Neurol 142:257-273, 1971.

VAN DEN BERGE H, VAN DER WAL JC. The innervation of the middle ear muscles of the rat. J. Anat 170:99-109, 1990.

WARR WB. Fiber degeneration following lesions in the multipolar and globular cell areas in the ventral cochlear nucleus of the cat. Brain Res 40:247-270, 1972.

Wiener-Vacher SR, Guinan JJ, Jr., Kobler JB, Norris BE. Motoneuron axon distribution in the cat stapedius muscle. Hear. Res 133:139-148, 1999.

Windsor A, Roska B, Brown MC, Lee DJ. Transneuronal analysis of the middle ear muscle reflex pathways using pseudorabies virus. Abstr. Assoc. Res. Otolaryngol. 30, 2007. 